\title{
Prediksi Jumlah Produksi Jenang di PT Menara Jenang Kudus Menggunakan Metode Logika Fuzzy Tsukamoto
}

\section{Jenang Production Prediction at Menara Jenang Kudus Using Fuzzy Tsukamoto}

\author{
Tatak Ulul Azmi ${ }^{1}$, Hanny Haryanto ${ }^{2}$, T.Sutojo ${ }^{3}$ \\ ${ }^{1,2,3}$ Program Studi Teknik Informatika - S1 \\ Fakultas Ilmu Komputer \\ Universitas Dian Nuswantoro, Jl. Nakula 1 No. 5-11, Semarang \\ 111201206926@mhs.dinus.ac.id ${ }^{1}$, hanny.haryanto@dsn.dinus.ac.id ${ }^{2}$, tsutojo@gmail.com $^{3}$
}

\begin{abstract}
Abstrak
Penelitian ini akan membahas tentang permasalahan yang terjadi pada PT. Menara Jenang Kudus, yaitu kesulitan dalam memprediksi jumlah produksi jenang perbulannya. Setiap bulannya penjualan jenang meningkat dan pihak perusahaan hanya mengandalkan perhitungan secara manual untuk menentukan jumlah produksi jenang pada bulan berikutnya. Dengan menggunakan perhitungan secara manual kadang terjadi kelebihan produksi yang mengakibatkan jenang menjadi basi karena jumlah produksi tidak sesuai dengan permintaan. Untuk dapat mengatasi permasalahan ini dan membantu mempermudah dalam memprediksi jumlah produksi Jenang perbulannya, maka diperlukan sistem untuk memprediksi secara otomatis menggunakan kecerdasan buatan. Logika fuzzy adalah sebuah metode dalam kecerdasan buatan yang menggunakan variabel kata-kata sebagai pengganti berhitung dengan bilangan. Dengan logika fuzzy, sistem kepakaran manusia bisa diimplementasikan ke dalam bahasa mesin secara mudah dan efisien. Logika fuzzy diaplikasikan untuk data di PT. Menara Jenang Kudus dari bulan Februari sampai September dengan hasil dari pengujian menggunakan MSE untuk Jenang Wijen sebesar 7.121, jenang spesial sebesar 15.940 dan Jenang Duren sebesar 21.168, yang menunjukkan bahwa meskipun terjadi error namun hasil prediksi masih dapat diterima.
\end{abstract}

Kata Kunci-Fuzzy Tsukamoto, jenang, kecerdasan buatan, produksi, prediksi

\begin{abstract}
This research will discuss about the problems that happened at PT. Jenang Kudus Tower, namely the difficulty in predicting the number of monthly production of jenang. Every month the jenang sales increase and the company only rely on the calculations manually to determine the amount of jenang production in the next month. By using manual calculations, there is sometimes an overproduction that causes the jenang to become stale because the amount of production does not match the demand. To be able to overcome this problem and help make it easier to predict the amount of monthly Jenang production, then the system is required to predict automatically using artificial intelligence. Fuzzy logic is a method in artificial intelligence that uses word variables instead of counting with numbers. With fuzzy logic, human expertise systems can be implemented into machine languages easily and efficiently. Fuzzy logic is applied to data in PT. Tower Jenang Kudus from February to September with the results of the test using MSE for Jenang Wijen of 7,121, Jenang Spesial of 15,940 and Jenang Duren of 21,168, indicating that despite error but predicted results are still acceptable.
\end{abstract}

Keywords -Fuzzy Tsukamoto, jenang, artificial intelligence, production, prediction 


\section{PENDAHULUAN}

Kota Kudus merupakan salah satu kota yang terletak di bagian utara Jawa Tengah yang mempunyai perkembangan cukup pesat terutama dalam bidang industri dan manufaktur. Perkembangan yang cukup pesat ini didukung antara lain karena letaknya yang strategis. Kondisi ini mendorong sektor industri dan perdagangan mampu berkembang dengan baik[1]. Kudus memiliki makanan khas, yaitu salah satunya jenang kudus. Jenang merupakan makanan sejenis dodol garut. Jenang menjadi makanan tradisional Jawa yang telah turun temurun diwariskan oleh nenek moyang dari dulu dan sekarang masih menjadi suatu makanan khas tradisional, khususnya di Jawa [1]. Industri PT Menara Jenang Kudus dari tahun ke tahun sering mengalami peningkatan jumlah produksi yang banyak terutama pada bulan-bulan yang mempunyai banyak hari raya [1]. Dalam suatu perusahaan produksi harus dapat menghitung prediksi dengan tepat dari segi hal jumlah produksi yang akan diproduksi, agar produk yang dibuat tidak mengalami basi [2]. Berdasarkan data di bagian penjualan jenang di PT. Menara Jenang Kudus, produksi mengalami peningkatan 5\% setiap bulannya, sedangkan pada saat Lebaran tiba penjualan bisa sampai $10 \%$ hingga 15\% dan di PT. Menara Jenang Kudus hanya mengandalkan prediksi penghitungan secara manual menggunakan kalkulator dan catatan buku dalam memproduksi jenang pada tiap bulannya [2]. Dalam hal ini tentunya akan membuat pihak perusahaan kesulitan untuk mengetahui jumlah produk yang harus diproduksi. Untuk dapat mengatasi permasalahan ini dan dapat meningkatkan kinerja dari perusahaan, maka diperlukan proses prediksi secara otomatis menggunakan kecerdasan buatan dengan metode logika fuzzy.

Beberapa penelitian yang mengunakan metode fuzzy pada studi kasus produksi suatu barang. Penelitian yang dilakukan oleh [3] membahas tentang bagaimana cara memproses prediksi secara otomatis menggunakan kecerdasan buatan, karena dalam setiap bulannya penjualan roti meningkat dan pihak perusahaan hanya mengandalkan prediksi tradisional dalam memproduksi roti pada tiap bulannya. Bentuk produksi yang dilakukan dalam jumlah yang sama dari hari ke hari tanpa adanya perhitungan terlebih dahulu. Di tahun yang sama dengan penelitian yang dilakukan oleh [4] membahas tentang penggunaan Fuzzy Tsukamoto untuk menentukan jumlah produksi barang".

Penelitian ini membahas tentang Metode fuzzy tsukamoto merupakan metode yang dapat digunakan dalam pengambilan keputusan untuk menentukan jumlah produksi barang. Metode fuzzy Tsukamoto ini dipilih karena setiap konsekuen pada aturan yang berbentuk IFTHEN direpresentasikan dengan menggunakan himpunan fuzzy pada fungsi keanggotaan yang monoton. Sebagai hasilnya, output dari setiap aturan kemudian diperoleh hasil akhir dengan menggunakan rata-rata terpusat. Pada perusahaan yang bergerak dalam bidang produksi barang. Metode fuzzy masih jarang digunakan dalam pengambilan keputusan produksi perusahaan. Perhitungan manual membutuhkan data-data permintaan maksimum pada periode tertentu, permintaan minimum pada periode tertentu, persediaan maksimum pada periode tertentu, persediaan minimum pada periode tertentu, produksi maksimum pada periode tertentu, produksi minimum pada periode tertentu, permintaan barang saat ini, dan persediaan barang saat ini. Jika menggunakan perhitungan secara manual membutuhkan waktu yang cukup lama, untuk itu perlu sistem pendukung keputusan dalam menentukan jumlah barang, sehingga dapat membantu mempermudah manager dalam pengambilan keputusan produksi. Di tahun yang sama penelitian juga dilakukan oleh Mutammimul Ula [5] yang berjudul "Implementasi Logika Fuzzy Dalam Optimasi Jumlah Pengadaan Barang Menggunakan Metode Tsukamoto". Pengadaan suatu barang yang masih menggunakan perhitungan manual sudah tidak mampu untuk melayani kebutuhan konsumen dalam proses penjualan yang cukup banyak. Dalam perhitungan yang saat ini menggunakan manual sudah tidak efektif dalam kinerjanya, tidak jarang pengadaan barang perhitungannya kurang tepat sasaran dalam hal prioritas barang dan terkadang terjadi pengadaan barang dengan jumlah yang berlebihan, hal ini dapat mengakibatkan pemborosan dana. Dari permasalahan ini peran komputer akan sangat membantu dan mempermudah dalam transaksi 
dan mengatur persediaan barang tidak hanya mengandalkan buku catatan. Dengan adanya sistem implementasi ini maka diharapkan dalam proses pelaksanaan penjualan produk menjadi lebih optimal dan meningkat. Dengan sistem Implementasi ini untuk melakukan fungsi pengolahan data, menerima masukan (input) dan menghasilkan keluaran (output) berupa informasi sebagai dasar bagi pengambilan keputusan sehingga dapat mencapai suatu tujuan yang di inginkan. Di tahun yang sama Penelitian dilakukan oleh Iklila Muzayyanah, Wayan Firdaus Mahmudy, Imam Cholissodin [6] yang berjudul "Penentuan Persediaan Bahan Baku Dan Membantu Target Marketing Industri Dengan Metode Fuzzy Inference System Tsukamoto". Bagaimana menghasilkan sebuah sistem cerdas yang membantu memprediksi jumlah produksi yang menjadi acuan dalam menentukan kebutuhan bahan baku industri dan dapat menghitung prediksi laba yang akan diperoleh berdasarkan dari perkiraan produksi dan kebutuhan bahan baku. Dalam pembahasan ini ketersediaan bahan baku yang tepat sangat terkait dengan jumlah produk yang akan diproduksi, dengan ini prediksi produksi harus disesuaikan agar pemesanan stok bahan baku dapat diperhitungkan dengan tepat.

Ketidak pastian jumlah permintaan dan stok produk dalam gudang yang ada pada suatu industri menjadi suatu hal yang harus diperhitungkan dalam memprediksi suatu produk. Dalam produksi untuk menentukan jumlah produk masih menggunakan prediksi tiap permintaan dan jumlah stok gudang secara manual. Hal ini sangat berpengaruh pada bahan baku yang harus di beli dari supplier dengan menggunakan prediksi secara manual. Dalam pembuatan sistem cerdas ini menggunakan metode fuzzy tsukamoto karena merupakan suatu metode yang dapat memprediksi dan memberikan toleransi data-data yang tidak tepat misalkan data permintaan dan stok gudang yang sangat mudah di prediksi dan sulit untuk di prediksi menggunakan perhitungan manual. Pada tahun 2015 Ahmad Zarkasi, Naniek Widyastuti, Erna Kumalasari [7] melakukan penelitian yang serupa dengan judul "Penerapan sistem pendukung keputusan metode fuzzy tsukamoto dalam pengoptimalan produksi barang berdasarkan data persediaan dan jumlah permintaan di loverandliars cloth". Penelitian ini membahas tentang produksi baju menggunakan metode fuzzy tsukamoto dengan menerapkan sistem penunjang keputusan (SPK) untuk menentukan banyak produksi barang berdasarkan data persediaan dan data jumlah permintaan.

\section{METODE PENELITIAN}

Penelitian ini dilakukan dengan menggunakan data jumlah produksi jenang wijen, jenang spesial, dan data jenang duren di PT. Menara Jenang Kudus bulan Januari-September tahun 2016. Data yang diperoleh dari PT. Menara Jenang Kudus terdiri dari 4 variabel yaitu retur, sisa, penjualan, produksi. Berikut adalah keterangan dan penjelasan data yang didapatkan.

Tabel 1 Data Retur Jenang bulan Januari-September 2016

\begin{tabular}{|l|l|l|l|}
\hline \multirow{2}{*}{ BULAN } & \multicolumn{3}{|c|}{ JENIS JENANG } \\
\cline { 2 - 4 } & \multicolumn{1}{|c|}{ Wijen } & \multicolumn{1}{|c|}{ Spesial } & Jenang rasa duren \\
\hline Januari & 3 ons & 1 ons & 1 ons \\
\hline Februari & 3 ons & 1 ons & 1 ons \\
\hline Maret & 3 ons & 1 ons & 1 ons \\
\hline April & 3 ons & 1 ons & 1 ons \\
\hline Mei & 3 ons & 1 ons & 1 ons \\
\hline Juni & 3 ons & 1 ons & 1 ons \\
\hline Juli & 5 ons & 3 ons & 1 ons \\
\hline Agustus & 3 ons & 1 ons & 1 ons \\
\hline September & 3 ons & 1 ons & 1 ons \\
\hline
\end{tabular}


Prediksi Jumlah Produksi Jenang ...

Tabel 2 Data Penjualan Jenang bulan Januari-September 2016

\begin{tabular}{|l|l|l|l|}
\hline \multirow{2}{*}{ BULAN } & \multicolumn{3}{|c|}{ JENIS JENANG } \\
\cline { 2 - 4 } & Wijen & \multicolumn{1}{|c|}{ Spesial } & Jenang rasa duren \\
\hline Januari & $140 \mathrm{~kg}$ & $48 \mathrm{~kg}$ & $38 \mathrm{~kg}$ \\
\hline Februari & $129 \mathrm{~kg}$ & $58 \mathrm{~kg}$ & $47 \mathrm{~kg}$ \\
\hline Maret & $178 \mathrm{~kg}$ & $57 \mathrm{~kg}$ & $49 \mathrm{~kg}$ \\
\hline April & $117 \mathrm{~kg}$ & $37 \mathrm{~kg}$ & $32 \mathrm{~kg}$ \\
\hline Mei & $165 \mathrm{~kg}$ & $40 \mathrm{~kg}$ & $33 \mathrm{~kg}$ \\
\hline Juni & $116 \mathrm{~kg}$ & $32 \mathrm{~kg}$ & $30 \mathrm{~kg}$ \\
\hline Juli & $354 \mathrm{~kg}$ & $114 \mathrm{~kg}$ & $96 \mathrm{~kg}$ \\
\hline Agustus & $125 \mathrm{~kg}$ & $48 \mathrm{~kg}$ & $44 \mathrm{~kg}$ \\
\hline September & $238 \mathrm{~kg}$ & $75 \mathrm{~kg}$ & $65 \mathrm{~kg}$ \\
\hline
\end{tabular}

Tabel 3 Data Sisa Jenang bulan Januari-September 2016

\begin{tabular}{|l|l|l|l|}
\hline \multirow{2}{*}{ BULAN } & \multicolumn{3}{|c|}{ JENIS JENANG } \\
\cline { 2 - 4 } & Wijen & Spesial & Jenang rasa duren \\
\hline Januari & 25 & 12 & 5 \\
\hline Februari & 9 & 8 & 4 \\
\hline Maret & 15 & 13 & 8 \\
\hline April & 8 & 5 & 3 \\
\hline Mei & 15 & 9 & 8 \\
\hline Juni & 7 & 6 & 3 \\
\hline Juli & 25 & 15 & 12 \\
\hline Agustus & 14 & 6 & 4 \\
\hline September & 17 & 12 & 11 \\
\hline
\end{tabular}

Tabel 4 Data Produksi Jenang bulan Januari-September 2016

\begin{tabular}{|l|l|l|l|}
\hline \multirow{2}{*}{ BULAN } & \multicolumn{3}{|c|}{ JENIS JENANG } \\
\cline { 2 - 4 } & Wijen & \multicolumn{1}{c|}{ Spesial } & Jenang rasa duren \\
\hline Januari & $150 \mathrm{~kg}$ & $50 \mathrm{~kg}$ & $40 \mathrm{~kg}$ \\
\hline Februari & $130 \mathrm{~kg}$ & $40 \mathrm{~kg}$ & $30 \mathrm{~kg}$ \\
\hline Maret & $180 \mathrm{~kg}$ & $60 \mathrm{~kg}$ & $50 \mathrm{~kg}$ \\
\hline April & $120 \mathrm{~kg}$ & $40 \mathrm{~kg}$ & $35 \mathrm{~kg}$ \\
\hline Mei & $170 \mathrm{~kg}$ & $45 \mathrm{~kg}$ & $35 \mathrm{~kg}$ \\
\hline Juni & $120 \mathrm{~kg}$ & $40 \mathrm{~kg}$ & $35 \mathrm{~kg}$ \\
\hline Juli & $360 \mathrm{~kg}$ & $120 \mathrm{~kg}$ & $100 \mathrm{~kg}$ \\
\hline Agustus & $130 \mathrm{~kg}$ & $50 \mathrm{~kg}$ & $45 \mathrm{~kg}$ \\
\hline September & $240 \mathrm{~kg}$ & $80 \mathrm{~kg}$ & $67 \mathrm{~kg}$ \\
\hline
\end{tabular}


Dalam merancang Fuzzy Tsukamoto yang digunakan untuk memprediksi jumlah produksi Jenang di PT. Menara Jenang Kudus meliputi kriteria, fuzzifikasi, pembentukan rule, defuzzifikasi, dan pengujian.

1. Kriteria

Kriteria yang digunakan dalam prediksi jumlah produksi Jenang menggunakan

Fuzzy Tsukamoto pada PT. Menara Jenang Kudus yaitu
a. Retur
b. Penjualan
c. Sisa
d. Produksi

\section{Fuzzifikasi}

Berdasarkan kriteria yang digunakan untuk memprediksi jumlah produksi Jenang menggunakan Fuzzy Tsukamoto pada PT. Menara Jenang Kudus ada 3 variabel yang dapat dimodelkan yaitu retur, penjualan dan sisa.

a.

$$
\text { Kriteria Retur }
$$

Dari hasil wawancara oleh pihak pemilik PT. Menara Jenang Kudus dibilang turun jika $<=0,5$ sedang antara 0,5 sampai 5 dan naik jika $>=5$. Kriteria retur terbagi menjadi 3 himpunan fuzzy, yaitu TURUN [0 2], SEDANG [0,5 5], NAIK [2 $\infty$ ]. Himpunan TURUN dan NAIK menggunakan pendekatan fungsi keanggotaan yang berbentuk bahu, sedangkan himpunan SEDANG menggunakan pendekatan berbentuk segitiga

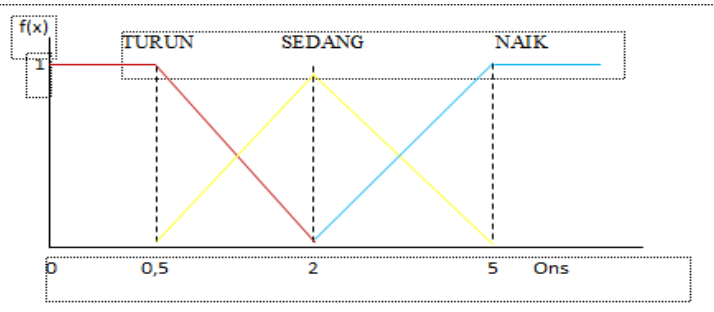

Gambar 1 Fungsi Keanggotaan pada Kriteria Retur

Fungsi keanggotaan pada kriteria retur dirumuskan sebagai berikut :

$$
\begin{aligned}
& \text { RetumTURUN }\left[x_{2}\right] \begin{cases}\frac{2-x_{2}}{1,5} & 0,5<x_{2}<2 \\
0 & x_{2} \geq 2\end{cases} \\
& \text { RetumSEDANG }\left[x_{2}\right] \\
& \text { RetumNAIK }\left[x_{2}\right]
\end{aligned} \begin{cases}\frac{0,5}{1,5} & x_{2} \leq 0,5 \text { atau } x_{2} \geq 5 \\
\frac{x_{2}-0,5<x_{2}<2}{1,5} & 2 \leq x_{2} \leq 5 \\
\frac{5-x_{2}}{3} & x_{2} \leq 2 \\
\frac{x_{2}-2}{3} & 2<x_{2}<5 \\
1 & x_{2} \geq 5\end{cases}
$$

Rumus (1) di atas akan digunakan untuk fuzzifikasi pada retur Jenang Wijen, Jenang Spesial dan Jenang Duren. 
b. Kriteria Penjualan

Dari hasil wawancara oleh pihak pemilik PT. Menara Jenang Kudus dibilang sedikit jika $\langle=25 \mathrm{~kg}$, sedang antara $25 \mathrm{~kg}$ sampai $385 \mathrm{~kg}$ dan banyak jika $>=385 \mathrm{~kg}$. Kriteria produksi terbagi menjadi 3 himpunan fuzzy, yaitu SEDIKIT [ $\left.\begin{array}{ll}0 & 205 \mathrm{~kg}\end{array}\right]$, SEDANG [25kg $385 \mathrm{~kg}$ ], BANYAK $[205 \mathrm{~kg} \infty]$. Himpunan SEDIKIT dan BANYAK menggunakan pendekatan fungsi keanggotaan yang berbentuk bahu, sedangkan himpunan SEDANG menggunakan pendekatan berbentuk segitiga pada gambar 2

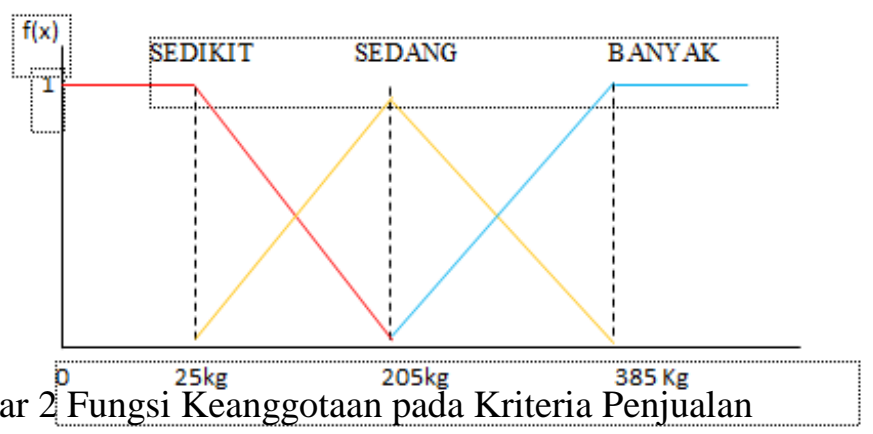

Fungsi keanggotaan pada kriteria penjualan dirumuskan sebagai berikut :

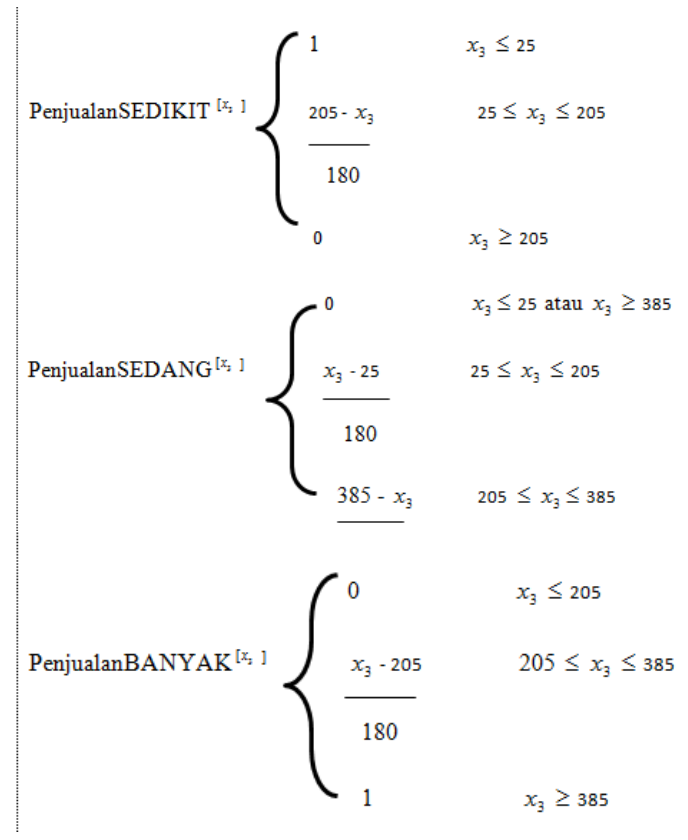

Rumus (2) di atas akan digunakan untuk fuzzifikasi pada penjualan Jenang Wijen, Jenang Spesial dan Jenang Duren.

\section{c. Kriteria Sisa}

Dari hasil wawancara oleh pihak pemilik PT. Menara Jenang Kudus dibilang sedikit jika $<=2$ ons, sedang antara 2ons sampai 20ons dan banyak jika $>=20$ ons. Kriteria produksi terbagi menjadi 3 himpunan fuzzy, yaitu SEDIKIT [0 10], SEDANG [2 20], BANYAK [20 $\infty$ ]. Himpunan SEDIKIT dan BANYAK menggunakan pendekatan fungsi keanggotaan yang berbentuk bahu, sedangkan himpunan SEDANG menggunakan pendekatan berbentuk segitiga seperti gambar 3 


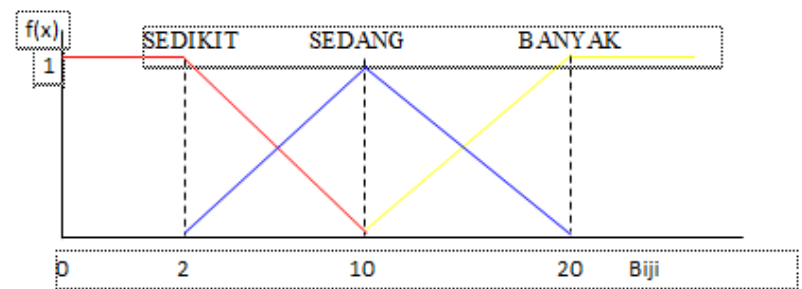

Gambar 3 Fungsi Keanggotaan pada Kriteria Sisa

Fungsi keanggotaan pada kriteria sisa dirumuskan sebagai berikut :

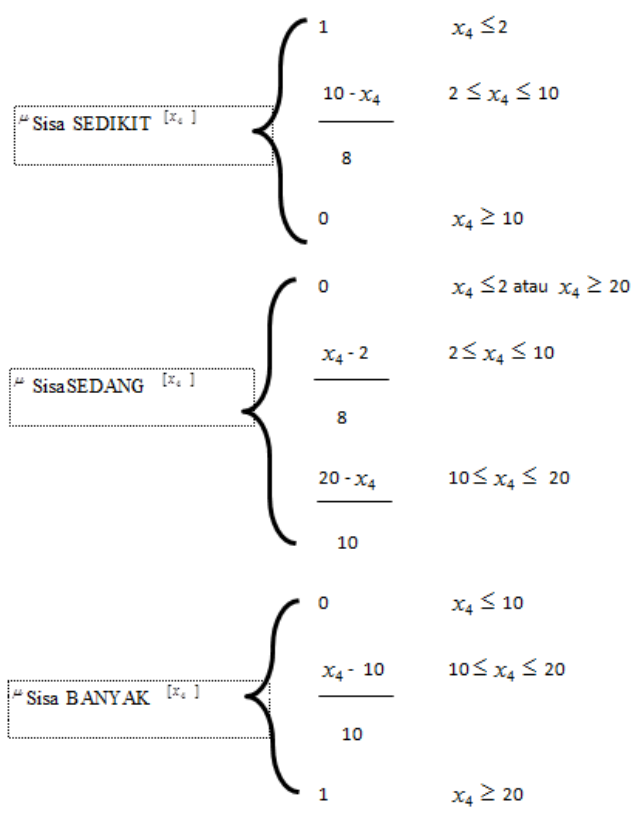

Rumus (3) di atas akan digunakan untuk fuzzifikasi pada sisa Jenang Wijen, Jenang Spesial, dan Jenang Duren

d.

Kriteria Produksi

Dari hasil wawancara oleh pihak pemilik PT. Menara Jenang Kudus dibilang berkurang jika $<=115 \mathrm{~kg}$, sedang antara $115 \mathrm{~kg}$ sampai $395 \mathrm{~kg}$ dan bertambah jika $>=395 \mathrm{~kg}$. Kriteria produksi terbagi menjadi 3 himpunan fuzzy, yaitu BERKURANG [0 255kg], SEDANG [115kg $395 \mathrm{~kg}]$, BERTAMBAH [255kg $\infty]$. Himpunan BERKURANG dan BERTAMBAH menggunakan pendekatan fungsi keanggotaan yang berbentuk bahu, sedangkan himpunan SEDANG menggunakan pendekatan berbentuk segitiga seperti gambar 4. 


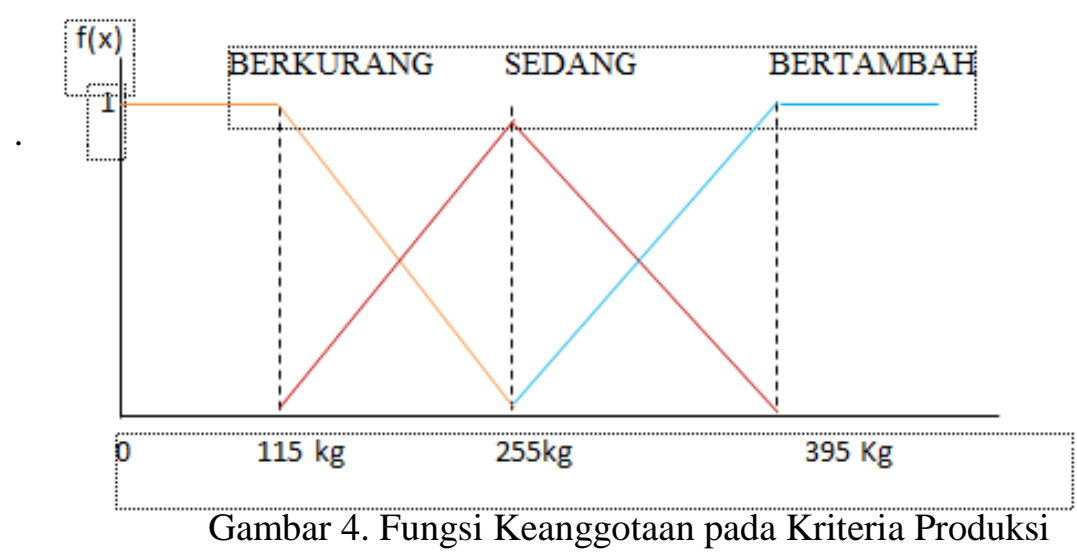

Fungsi keanggotaan pada kriteria produksi dirumuskan sebagai berikut:

$$
\begin{aligned}
& \text { ProduksiBERKURANG }{ }^{\left[x_{2}\right]}\left\{\begin{array}{cc}
1 & x_{1} \leq 115 \\
\frac{255-x_{1}}{140} & 115 \leq x_{1} \leq 255 \\
0 & x_{1} \geq 255
\end{array}\right. \\
& \text { ProduksiSEDANG }^{\left[x_{2}\right]} \begin{cases}0 & x_{1} \leq 115 \text { atau } x_{1} \geq 395 \\
\frac{x_{1}-115}{140} & 115 \leq x_{1} \leq 255 \\
395-x_{1} & 255 \leq x_{1} \leq 395\end{cases} \\
& \text { ProduksiBERTAMBAH }^{\left[x_{2}\right]} \begin{cases}0 & x_{1} \leq 255 \\
\frac{x_{1}-255}{140} & 255 \leq x_{1} \leq 395 \\
1 & x_{1} \geq 395\end{cases}
\end{aligned}
$$

Rumus (4) di atas akan digunakan untuk fuzzifikasi pada produksi Jenang Wijen, Jenang Spesial dan Jenang Duren

3. Pembentukan rule

Hasil Rule dalam memprediksi jumlah produksi Jenang menggunakan Fuzzy Tsukamoto pada PT. Menara Jenang Kudus seperti pada tabel 
Tabel 5. Rule

\begin{tabular}{|c|l|l|l|l|}
\hline \multirow{2}{*}{ RULE } & \multicolumn{3}{|c|}{ IF } & THEN \\
\cline { 2 - 5 } & Retur & Penjualan & Sisa & Produksi \\
\hline R1 & Turun & Banyak & Banyak & Sedang \\
\hline R2 & Turun & Banyak & Sedang & Sedang \\
\hline R3 & Turun & Banyak & Sedikit & Bertambah \\
\hline R4 & Turun & Sedang & Banyak & Sedang \\
\hline R5 & Turun & Sedang & Sedang & Sedang \\
\hline R6 & Turun & Sedang & Sedikit & Bertambah \\
\hline R7 & Turun & Sedikat & Banyak & Berkurang \\
\hline R8 & Turun & Sedilait & Sedang & Berkurang \\
\hline R9 & Turun & Sedilait & Sedikit & Sedang \\
\hline R10 & Sedang & Banyak & Banyak & Sedang \\
\hline R11 & Sedang & Banyak & Sedang & Sedang \\
\hline R12 & Sedang & Banyak & Sedikit & Bertambah \\
\hline R13 & Sedang & Sedang & Banyak & Sedang \\
\hline R14 & Sedang & Sedang & Sedang & Sedang \\
\hline R15 & Sedang & Sedang & Sedikit & Sedang \\
\hline R16 & Sedang & Sedikat & Banyak & Berkurang \\
\hline R17 & Sedang & Sedikit & Sedang & Berkurang \\
\hline
\end{tabular}

\begin{tabular}{|l|l|l|l|l|} 
R18 & Sedang & Sedikit & Sedikit & Berkurang \\
\hline R19 & Naik & Banyak & Banyak & Sedang \\
\hline R20 & Naik & Banyak & Sedang & Sedang \\
\hline R21 & Naik & Banyak & Sedikät & Sedang \\
\hline R22 & Naik & Sedang & Banyak & Sedang \\
\hline R23 & Naik & Sedang & Sedang & Sedang \\
\hline R24 & Naik & Sedang & Sedikit & Sedang \\
\hline R25 & Naik & Sedikit & Banyak & Berkurang \\
\hline R26 & Naik & Sedikit & Sedang & Berkurang \\
\hline R27 & Naik & Sedikit & Sedikit & Berkurang \\
\hline
\end{tabular}

4. Defuzifikasi

Defuzzifikasi dalam memprediksi jumlah produksi Jenang menggunakan Fuzzy Tsukamoto di PT. Menara Jenang Kudus dicari dengan menggunakan rata-rata terbobot dengan rumus sebagai berikut .

$$
y=\sum \frac{\mu(y) y}{\mu(y)}
$$

Dimana $y$ adalah nilai crisp dan $\mu(y)$ adalah derajat keanggotaan dari $y$.

5. Pengujian

Pengujian akan dilakukan terhadap data jumlah produksi dari PT. Menara Jenang Kudus dari bulan Januari sampai September 2016 menggunakan Mean Square Error (MSE) dengan rumus sebagai berikut :

$$
\frac{\sum(\text { data hasil prediksi }- \text { data asli })^{2}}{\text { jumlah data }}
$$

\section{HASIL DAN PEMBAHASAN}

Dalam penelitian ini diperlukan Pengujian terhadap data jumlah produksi Jenang di PT. Menara Jenang Kudus dari bulan Januari sampai September 2016 menggunakan Mean Square Error (MSE) yaitu : 
Prediksi Jumlah Produksi Jenang ...

$\begin{array}{lll}\text { MAE } & =130-197 \quad=-67 \\ \text { MSE } & =-67^{2} \quad=4.489 \\ \text { Rata-rataMSE } & =(4.489+100+5.041+256+5.184+30.625+8.464+ \\ & \\ & & \\ & =\frac{56.809)}{8} & 8\end{array}$

Tabel 6 Hasil Pengujian Sistem Jenang Wijen

\begin{tabular}{|c|c|c|c|c|}
\hline Bulan & $\begin{array}{c}\text { Jenang } \\
\text { Wijen }\end{array}$ & $\begin{array}{c}\text { Hasil Prediksi } \\
\text { Jenang Wijen } \\
(\mathbf{K g})\end{array}$ & MAE & MSE \\
\hline Februari & 130 & 197 & -67 & 4.489 \\
\hline Maret & 180 & 190 & -10 & 100 \\
\hline April & 120 & 191 & -71 & 5.041 \\
\hline Mei & 170 & 186 & -16 & 256 \\
\hline Juni & 120 & 192 & -72 & 5.184 \\
\hline Juli & 360 & 185 & 175 & 30.625 \\
\hline Agustus & 130 & 222 & -92 & 8.464 \\
\hline September & 240 & 187 & 53 & 2.809 \\
\hline \multicolumn{5}{|c|}{ Rata-rata MSE } \\
\hline
\end{tabular}

Hasil dari pengujian sistem Jenang Wijen di PT. Menara Jenang Kudus dari bulan februari-september dengan jumlah rata-rata MSE sebesar 7.121

Tabel 7 Hasil Pengujian Sistem Jenang Spesial

\begin{tabular}{|c|c|c|c|c|}
\hline Bulan & $\begin{array}{c}\text { Jenang } \\
\text { Spesial }\end{array}$ & $\begin{array}{c}\text { Hasil Prediksi } \\
\text { Jenang Spesial } \\
\text { (Kg) }\end{array}$ & MAE & MSE \\
\hline Februari & 40 & 176 & -136 & 18.496 \\
\hline Maret & 60 & 178 & -118 & 13.924 \\
\hline April & 40 & 175 & -135 & 18.225 \\
\hline Mei & 45 & 199 & -154 & 23.716 \\
\hline Juni & 40 & 175 & -135 & 18.225 \\
\hline Juli & 120 & 191 & -71 & 5.041 \\
\hline Agustus & 50 & 185 & -135 & 18.225 \\
\hline September & 80 & 188 & -108 & 11.664 \\
\hline \multicolumn{5}{|c|}{ Rata-rata MSE } \\
\hline
\end{tabular}

Hasil dari pengujian sistem Jenang Spesial di PT. Menara Jenang Kudus dari bulan februari-september dengan jumlah rata-rata MSE sebesar 15.940

Tabel 8 Hasil Pengujian Sistem Jenang Duren

\begin{tabular}{|c|c|c|c|c|}
\hline Bulan & $\begin{array}{c}\text { Jenang } \\
\text { Duren }\end{array}$ & $\begin{array}{c}\text { Hasil Prediksi } \\
\text { Jenang Duren } \\
\text { (Kg) }\end{array}$ & MAE & MSE \\
\hline Februari & 30 & 198 & -168 & 28.224 \\
\hline Maret & 50 & 201 & -151 & 22.801 \\
\hline April & 35 & 177 & -142 & 20.164 \\
\hline Mei & 35 & 208 & -173 & 29.929 \\
\hline Juni & 35 & 177 & -142 & 20.164 \\
\hline Juli & 100 & 209 & -109 & 11.881 \\
\hline Agustus & 45 & 179 & -134 & 17.956 \\
\hline September & 67 & 202 & -135 & 18.225 \\
\hline \multicolumn{5}{|c|}{ Rata-rata MSE } \\
\hline
\end{tabular}

Hasil dari pengujian sistem Jenang Duren di PT. Menara Jenang Kudus dari bulan februari-september dengan jumlah rata-rata MSE sebesar 21.168 


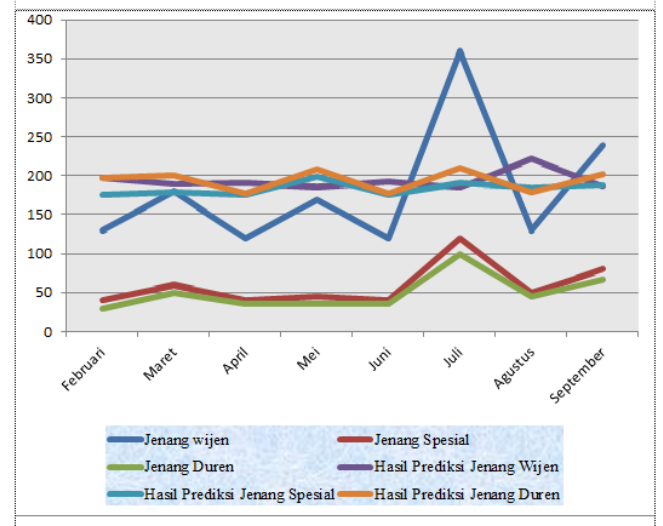

Gambar 5 Grafik Produksi dan hasil prediksi

Dari grafik produksi dan hasil prediksi diatas berisi tentang bulan Februari-September 2016 selanjutnya warna biru menunjukan data Jenang wijen, warna hijau menunjukan data Jenang duren, dan warna merah tua menunjukan data Jenang Spesial sedangkan warna biru muda menunjukan hasil prediksi Jenang Spesial, warna ungu menunjukan hasil prediksi Jenang wijen dan warna orange menunjukan hasil prediksi Jenang duren.

Hasil MSE menunjukkan error yang cukup besar pada hasil prediksi, namun dibandingkan penelitian yang dilakukan oleh [3] yang menghasilkan nilai MSE sekitar 20 sampai 30, maka hasil penelitian ini menunjukkan peningkatan. Hal ini disebabkan karena lebih banyaknya data dan nilai variabel yang digunakan. Meskipun terdapat nilai error yang cukup besar, hasil prediksi dapat diterima dan digunakan untuk menentukan produksi jenang.

\section{KESIMPULAN}

Hasil prediksi jumlah produksi jenang menggunakan metode fuzzy tsukamoto pada PT. Menara Jenang Kudus memperlihatkan nilai MSE pada jenang wijen sebanyak 7.121, Jenang spesial sebanyak 15.940, Jenang duren sebanyak 21.168. Pada PT. Menara Jenang Kudus menampilkan hasil rekomendasi produksi jenang. Hasil rekomendasi produksi jenang ini hanya untuk mendukung keputusan pada prediksi jumlah produksi jenang, bukan untuk sistem penentu sebuah keputusan. Oleh sebab itu untuk memproduksi jenang tetap tergantung pada pengguna tidak harus menggunakan hasil rekomendasi yang ditampilkan.

\section{SARAN}

Berikut ini saran penulis terhadap pengembangan dan penerapan Logika fuzzy menggunakan metode fuzzy tsukamoto pada PT. Menara Jenang Kudus :

a. Diharapkan sistem prediksi untuk menentukan jumlah produksi jenang ini dapat dikembangkan, seperti menggabungkan metode fuzzy tsukamoto dengan metode fuzzy mamdani agar hasil produksinya bisa lebih sesuai.

b. Dalam menghitung produksi menggunakan metode fuzzy tsukamoto, dapat menambahkan kriteria yang diinginkan sistem yang sifatnya dinamik terdiri dari variabel input kriteria fuzzy. 


\section{DAFTAR PUSTAKA}

[1] I. Nihlah, 2011. Industri Jenang Mubarokfood Cipta Delicia dan Pengaruhnya Terhadap Sosial Ekonomi Masyarakat Glantengan tahun 1975-1998, Skripsi, Universitas Negeri Semarang.

[2] H. Nasution, "Implementasi Logika Fuzzy pada Sistem Kecerdasan Buatan," ELKHA, vol. 4, no. 2, pp. 4-8, 2012.

[3] Wiguna, Riyadi Y., 2015, Sistem berbasis aturan menggunakan logika fuzzy tsukamoto untuk prediksi jumlah produksi roti pada CV. gendis bakery, Skripsi, Fakultas Ilmu Komputer, Universitas Dian Nuswantoro Semarang.

[4] Ikhsan, Fathurrahman K., Penerapan Fuzzy Tsukamoto dalam Sistem Pendukung Keputusan Untuk Menentukan Jumlah Produksi Barang. Prosiding Sembistek, 2014.

[5] M. Ula, "Implementasi Logika Fuzzy Dalam Optimasi Jumlah Pengadaan Barang Menggunakan Metode Tsukamoto ( Studi Kasus : Toko Kain My Text )," ECTIPE, vol. 1, no. 2, 2014.

[6] I. Muzayyanah, W. F. Mahmudy, I. Cholissodin, Penentuan Persediaan Bahan Baku dan Membantu Target Marketing Industri dengan Metode Fuzzy Inference System Tsukamoto. DORO, vol. 4, no. 7, 2014.

[7] A. Zarkasi, N. Widyastuti, and E. K. N, Penerapan Sistem Pendukung Keputusan Metode Fuzzy Tsukamoto dalam Pengoptimalan Produksi Barang Berdasarkan Data Persediaan dan Jumlah Permintaan di Loverandliars Cloth. Jurnal Script, Vol. 3, no. 1, pp. 1-10, 2015. 